\title{
Activity cycles and foraging behaviors of free-ranging sidewinder rattlesnakes (Crotalus cerastes): the ontogeny of hunting in a precocial vertebrate
}

Rulon W. Clark ${ }^{\mathrm{a},}$, Scott W. Dorra, Malachi D. Whitford ${ }^{\mathrm{b}, 1}$, Grace A. Freymillera, Breanna J. Putmana,c

a Department of Biology, San Diego State University, 5500 Campanile Drive, San Diego, CA 92182, USA

${ }^{b}$ Department of Biological Sciences, Humboldt State University, 1 Harper Street, Arcata, CA 95521, USA

${ }^{c}$ Ecology Graduate Group, University of California, 1005 Wickson Hall, One Shields Avenue, Davis, CA 95616, USA

* Corresponding author.

E-mail address: rclark@mail.sdsu.edu (R.W. Clark).

${ }^{1}$ Present address: Department of Biology, San Diego State University, 5500 Campanile Drive, San Diego CA 92182, USA 


\section{Abstract}

Predators often employ a complex series of behaviors to overcome antipredator defenses and effectively capture prey. Although hunting behaviors can improve with age and experience, many precocial species are necessarily effective predators from birth. Additionally, many predators experience innate ontogenetic shifts in predatory strategies as they grow, allowing them to adapt to prey more appropriate for their increased size and energetic needs. Understanding how the relative roles of innate age-specific adaptation and learning have evolved requires information on how predation behavior develops in situ, in free-ranging predators. However, most of the research on the ontogeny of predation behavior is based on laboratory studies of captive animals, largely due to the difficulty of following newborn individuals in nature. Here, we take advantage of the unique tracks left by juveniles of a precocial viperid, the sidewinder rattlesnake (Crotalus cerastes), which we used to follow free-ranging snakes in the field. We recorded details of their ambush hunting behavior, and compared the behaviors of these juveniles to adult snakes that we monitored in the field via radio telemetry. Although juvenile and adult behaviors were similar in most respects, we did find that adults chose more effective ambush sites, which may be due to their increased experience. We also found that juveniles (but typically not adults) perform periodic tail undulations while in ambush, and that juveniles displayed slightly different activity cycles. Both of these latter differences are likely the result of age-specific adaptations for juveniles' greater reliance on lizards versus small mammals as prey. We also compared the general predatory behavior of sidewinders to that of other species in the genus Crotalus. These findings will provide important baseline field information for more detailed empirical research on the ontogeny of predation behavior in precocial vertebrates.

Keywords: Foraging behavior; Predation; Predator-prey interaction; Ambush hunting 


\section{Introduction}

Effective predation behavior is central to the reproductive success of all predators. Predation is inherently complex and dynamic because it involves predicting and responding to the behavior of another party; often, predators must overcome the antipredator adaptations of prey to be successful (Lima, 2002). For this reason, predation attempts often fail (Fanshawe and Fitzgibbon, 1993; Cresswell et al., 2010; Clark et al., 2012), and the reproductive success of many predators is food-limited (Wiehn and Korpimäki, 1997; Taylor et al., 2005; Ford et al., 2010).

Predation behavior can improve with age and experience. Many altricial species learn not only from direct experience, but also from mimicking the behavior of others: typically parents, but occasionally other conspecifics (Danchin, 2004). Many of these species benefit from a prolonged period of parental care, whereby parents provide food (Clutton-Brock, 1991) and experience (Caro, 1980; Thornton and McAuliffe, 2006). In contrast, juveniles of more precocial species must exhibit effective hunting from birth. These species exhibit innate development of complex predatory behaviors, such as construction of elaborate webs (Eberhard, 1982) or recognition and discrimination of specific chemosensory cues associated with appropriate prey (Burghardt, 1969).

Although many laboratory studies have demonstrated the direct development of speciestypical predatory behaviors, few have examined the additional role that experience may play in the expression of those behaviors. The research that has been done generally shows that individuals can modify their innate predatory behavior with experience. For example, with experience, hatchling trinket snakes improve in their ability to handle and ingest large prey (Mehta, 2008), orb-web spiders build more effective webs (Heiling and Herberstein, 1999), and sticklebacks improve in their handling and efficiency of prey capture (Croy and Hughes, 1991).

Such laboratory studies are useful in evaluating specific hypotheses, but they only represent the potential for such behaviors to occur in natural environments, where predation events may be rare and idiosyncratic. Field studies of individuals encountering prey in situ are needed to determine the extent to which experience may affect predation success, and ultimately reproductive success. However, examining the role of predation experience in the development of behavior in free-ranging animals is complicated by the 
possibility of innate ontogenetic changes. Because juvenile and adult individuals can be very different in size, movement, and microhabitat use, they may specialize on different prey types. Several studies have demonstrated that changes in morphology and behavior associated with predation can occur even in the absence of relevant experience, as individuals undergo innate development of age-appropriate traits (Ewert and Burghagen, 1979; Mushinsky and Lotz, 1980; Rabatsky and Waterman, 2005a; Robbins and Langkilde, 2012). Thus, in order to determine if age-related differences in free-ranging animals are based on learning and experience, some knowledge of the ecological context of predation behavior is necessary.

Examining ontogenetic changes associated with maturation is further complicated in many species by the difficulty in following young, usually small, individuals for long periods of time in nature. For example, the study of snake ecology and behavior in the field has been revolutionized by the widespread adoption of radio telemetry, but even miniaturized transmitters remain too large for effective use on small juveniles of most species (Újvári, 2000). Here, we take advantage of unique aspects of the microhabitat used by sidewinder rattlesnakes (Crotalus cerastes) to compare predation behaviors of free-ranging juvenile and adult snakes. We use traditional radio telemetry to monitor adults, and we locate juveniles by following their unique tracks left in the loose sand microhabitat this species prefers (Brown and Lillywhite, 1992; Secor, 1994). We use fixed videography to amass a large database of recordings of both juveniles and adults as they sit and wait in ambush for their prey. We then extract key data from recordings for data analysis, allowing us to evaluate potential ontogenetic changes in predation behavior in a population of freeranging individuals.

\section{Materials and methods}

\subsection{Study site and subjects}

Our study took place at a site in the Mohave Desert approximately $3 \mathrm{~km}$ south of the Desert Studies Center in San Bernardino County, California. This area is characterized by a mixture of loose wind-blown sand, alkali sink vegetation, and creosote bush scrub. Here, sidewinders are generally inactive during the overwintering period from November to March, and exhibit surface activity and feeding behavior from March to October; during the 
summer months (May-September), sidewinders are mainly nocturnal and remain inactive in thermal refuges (typically lizard or mammal burrows) from mid-morning until dusk (Brown and Lillywhite, 1992; Secor, 1994; Lima, 2002).

For the present study, we monitored sidewinder behavior from May to August, 2011-2014. We captured adult rattlesnakes and surgically implanted them with temperature-sensitive radio transmitters (model G3; AVM Instrument Company Ltd, CA, USA) following the methods of Reinert and Cundall (1982). Transmitters weighed less than 5\% of snake body mass. After resuming normal behavior following surgery all snakes were released in the field at their site of capture.

We collected data on 28 individual snakes, 13 adults and 15 juveniles. All adults were weighed with hanging scales accurate to $5 \mathrm{~g}$ and measured while lying straightened under anesthetic on a countertop during implantation of transmitters. All captured juveniles ( $\mathrm{n}=$ 9) were permanently marked with passive integrated transponder tags inserted subcutaneously and weighed with hanging scales accurate to $2 \mathrm{~g}$ and measured while unanesthetized and restrained in plastic handling tubes. All adults exhibited size and rattle characteristics that indicated they were at least 3 years of age or older (Brown and Lillywhite, 1992; Secor, 1994). Sidewinders give birth in the fall (August-October) to live young, which range in size from 16 to $21 \mathrm{~cm}$ total length (Brown and Lillywhite, 1992). All juveniles in our study exhibited size and rattle characteristics indicating they were in their first summer; that is, they had none or only one rattle segment below the natal button (the portion of the rattle present at birth) and were $\sim 30 \mathrm{~cm}$ in length (Secor, 1994). However, we only captured, tagged, and measured 8 of the 15 individuals for which we collected behavioral data. We collected videography data on the other 6 individuals without capturing them because they were exhibiting ambush coils upon location and we did not want to disturb their hunting behavior. We were able to visually assess their size during sand tracking to assure they were within the size range of our measured individuals. We are confident these snakes were unique individuals because they did not occur in a geographic area close to any juveniles similar in size that were monitored as part of the present study.

We typically radio tracked adults at least once daily, and every $2-3 \mathrm{~h}$ when monitoring via videography. Because juveniles would eventually move into areas where we could no 
longer follow their tracks, we were only able to follow individual juveniles for limited time periods. Upon relocation, any individuals that had moved more than $3 \mathrm{~m}$ were classified as having relocated to a new site, and we recorded their position using handheld GPS units. Snakes that had only moved short distances $(<3 \mathrm{~m})$ were categorized as remaining at the same site.

\subsection{Field videography}

We used video cameras connected to a wireless network to record snakes that were on the surface in stereotyped ambush coils (e.g., Clark, 2004a; Reinert et al., 2011). We used pan/tilt/zoom network security cameras (Sony SNC-RZ25N) connected to network radios (Ubiquiti NanoStation M2; Ubiquiti Networks, San Jose, CA, USA) that communicated with a base station (Ubiquiti PowerStation P5-EXT) mounted on a $10 \mathrm{~m}$ aluminum tower erected at the center of our field site. We used laptop computers in the field to monitor and record video feeds at 15 frames per second (fps) from multiple cameras recording snakes simultaneously. Whenever snakes were seen to abandon sites, we relocated them via radio telemetry or sand tracking, and moved cameras to continue recording hunting behavior of

snakes that adopted new ambush coils. Snakes were only active on the surface at night and always retreated to refugia (usually rodent or lizard burrows but occasionally very thick vegetation) during the day. Thus, we usually positioned cameras over their known daytime refugia and recorded snakes emerging onto the surface around dusk. If snakes were not visible on camera for more than approximately an hour after sunset (i.e., they remained in a burrow or vegetation), we checked their position via radio telemetry.

We extracted several video clips from our database that illustrate typical behaviors of both adults and juveniles. These clips are available through our laboratory YouTube channel. Names, descriptions, and URLs of clips are listed in Table 1.

\subsection{Behavioral quantification}

\subsubsection{Ambush sites}

We defined an ambush site as an area less than $3 \mathrm{~m}$ in diameter at which a snake exhibited stereotypical ambush coils. Snakes would often remain at ambush sites for more than one day, but would always retreat to nearby refugia during the heat of the day and emerge in 
the early to late evening to resume surface ambush coils. When resuming ambushing at the same site, snakes would often coil at or near (within $100 \mathrm{~cm}$ ) their previous night's position. Snakes would also sometimes shift positions while on the surface, moving 5-100 $\mathrm{cm}$ to coil at a slightly different location. Thus, at a given ambush site, snakes could exhibit multiple ambush coils at slightly different locations.

\subsubsection{Behavioral states}

For our analyses, we classified rattlesnakes into one of four behavioral states as follows: (1) Ambush hunting: snake is coiled tightly on the surface or just inside the entrance of a burrow; snake remains motionless, with the exception of occasional chemosensory probing (movement of the head and neck out of the coiled position accompanied by tongue flicks, sensu Barbour and Clark, 2012a), mouth gaping (Burghardt, 1969; Graves and Duvall, 1983), non-rattling tail undulation (slow, rhythmic waving or wiggling of the tail in an otherwise motionless coiled snake, similar to caudal luring behavior employed by many viperid snakes sensu Heatwole and Davison, 1976), or striking at prey. (2) Moving: snake is actively moving on the surface between ambush sites. (3) In burrow: snake is inside a lizard or mammal burrow and is not visible at the burrow entrance. (4) Loose coil: snake is on the surface in a loose coil typical of thermoregulation or pre-ecdysis (see Fig 4 in Reinert et al., 2011, for illustrations and further discussion of distinction between foraging and nonforaging coils in rattlesnakes).

For each ambush site, we estimated the time spent in different behavioral states to the nearest hour, and categorized daytime and nighttime hours separately. We used sunset/sunrise times for our field location to differentiate daytime and nighttime hours. Our estimates of times spent in some behavioral states are not more precise because snakes were not actively monitored while moving. We found that snakes were susceptible to disturbance when moving and so we did not typically approach moving snakes closely when conducting radio telemetry or tracking; instead, we periodically $(\sim 1-2 \mathrm{~h})$ checked individuals that had begun moving to determine their current behavioral state. However, on some occasions we checked snakes every 30-60 min and made qualitative observations of their behavior while moving. We used only this limited, more precise data set for our estimation of time spent moving between sites. When snakes had stopped moving and 
adopted another behavior, we estimated the endpoint of one behavioral state and the beginning of the subsequent state as the midpoint between the times that snakes had been checked. We used this same procedure to measure the onset of surface activity to the nearest hour; beginning at approximately 19:00 (which was prior to the emergence of nearly all snakes) we checked the location and behavioral state of snakes every 1-3 $\mathrm{h}$ each evening.

\subsubsection{Ambush hunting behaviors}

We used counts to characterize behaviors of snakes in an ambush hunting behavioral state (probing, mouth gaping, non-rattling tail undulation, striking). Because probing and mouth gaping were frequent and ubiquitous, we quantified the rates of these behaviors through subsampling. We randomly selected seven adults and seven juveniles and quantified probe and yawn rates throughout 4 randomly selected bouts of ambush hunting for each individual, for a total of 56 ambush hunting bouts.

We counted the occurrence of non-rattling tail undulation in bouts. A bout was defined as the snake conspicuously moving its tail back and forth in an undulatory fashion with no pause in tail movement for longer than $300 \mathrm{~s}$. Undulations that took place $>300 \mathrm{~s}$ apart were classified as separate bouts.

\subsubsection{Prey encounters}

Sidewinders prey on a range of small mammal and lizard species (Funk, 1965; Klauber, 1972; Brown and Lillywhite, 1992). Thus, we categorized as prey any lizard or mammal small enough to be ingested that is either a conspecific or congener of a known dietary item. Prey were identified to as fine a taxonomic level as possible using field guides and known geographic distributions. Prey encounters occurred when prey came within approximately $1 \mathrm{~m}$ of a snake, an estimated distance at which both rattlesnakes and their prey can typically detect each other (Clark et al., 2012). Prey were further classified as coming within strike range if they came within $25 \mathrm{~cm}$ of adults or $15 \mathrm{~cm}$ of juveniles, the furthest distances snakes were observed to strike.

We used a modified form of the procedure of Clark et al. (2012) to estimate distances from video frames. Briefly, we used ImageJ software (Abramoff et al., 2004) to determine 
distances in digitized images from videos, using snake head length to set the size scale in each image. Klauber (1972) published detailed measurements of the correlation between body length and head length of sidewinders by measuring several hundred individuals. Because we had measured the body length, but not head length, of our snakes, we used Klauber's published correlations to estimate each individual's head length. Because distance estimates are subject to some imprecision given the variation in camera angles and positions (Clark et al., 2012), we estimated distances to the nearest $5 \mathrm{~cm}$. We also estimated the precision of our approach of using the head to set size scales by having several different individuals independently use image $\mathrm{J}$ to generate a pixel per $\mathrm{cm}$ value for each of five randomly selected video frames from our data set that were used as frames to set the size standard for that field of view. We then calculated $95 \%$ confidence intervals (CIs) for these measurements, and used the $95 \%$ CIs to determine the value at which the CI would be greater than $5 \mathrm{~cm}$ (the value to which we rounded our distance estimates).

\subsubsection{Snake strikes}

Snakes occasionally attempted to strike prey that came within range. We categorized strikes as either hits or misses. Because rattlesnake strikes are extremely rapid, video recordings could be ambiguous with respect to outcome. Thus, strikes were categorized as hits if they met two criteria: (i) the head of the snake appeared to contact the prey in the video image, and (ii) snakes either held the prey until it was immobile, or released it and exhibited strike-induced chemosensory searching (SICS), a stereotyped behavior rattlesnakes use when relocating envenomated prey (Chiszar et al., 1992). Strikes were categorized as misses if the video clearly showed the head of the snake not contacting the prey, or, if contact was ambiguous, snakes did not exhibit SICS. We used the distance estimating technique detailed above (see Section 2.3.4) to estimate the minimum distance between the snake and the prey in the frame prior to the strike. Prey were categorized as dodging if they exhibited an abrupt change in movement trajectory following strike initiation. See Clark et al. (2012) for additional methodological details. Although the relatively low frame rates of our video recordings are not sufficient for quantifying the speed of strike movements with precision, they can provide information on the degree to which strike speed may vary under natural conditions. Thus, we counted the 
number of video frames encompassing strike extension and prey contact to provide some parameters for how variable these measures may be for free-ranging snakes striking at free-ranging prey. Strike extension is the time from which the head moves out of the ambush coil to when the snake contacts the prey (or, in the case of misses, the space occupied by prey that moved), and prey contact is the time from initial contact of prey by the snake to when that prey is no longer in contact with the head of the snake. In addition to the data we collected on prey encounters during our natural observations, we incidentally recorded an adult snake preying on a small rodent while collecting experimental data in the summer of 2014. We include this encounter in our analysis of strike behavior, but not in our analysis of encounter rates.

\subsection{Statistical analyses}

We used R version 3.0.2 (R Development Core Team, 2011) for all statistical analyses. We used linear mixed models implemented in the lme4 package to compare adults and juveniles with respect to emergence and ingress times, ambush site residence times, movement times, movement distances, and rates of chemosensory probing. Because we collected multiple samples per individual, we incorporated individual identity of snakes into the model as a random factor. We determined the significance of age (adult versus juvenile) by comparing models with and without age as a fixed factor using the KenwardRoger correction in the pbkrtest package.

Because we had more limited data on tail undulation and prey encounters, a mixed model framework was not well suited for analysis; instead, we made general comparisons using goodness-of-fit tests. We used chi-square goodness-of-fit tests when more than $80 \%$ of expected values were greater than five, and exact binomial tests otherwise. We also had a limited sample size of attempted strikes with which to explore factors related to strike success. Thus, we limited our analysis to our main factor of interest (snake age) and two a priori factors identified as important in Clark et al. (2012): prey dodging and distance. These three factors were assessed independently with univariate logistic regression. The 16 strike attempts came from 13 individuals; one snake was recorded striking on three separate occasions, another on two. Because each strike attempt involved independent prey under unique field circumstances (i.e., different spatial locations and times), we 
treated all 16 attempts as independent data points. We used linear regression to examine the effect of age on extend time for these strikes. Because several snakes held on to prey after striking, we only report descriptive statistics for contact time as we did not have an adequate sample size for statistical testing. We conducted logistic regression using penalized maximum likelihood in the logistf package, and linear regression using the stats package. All values are given as mean \pm standard deviation.

\section{Results}

\subsection{Study subjects}

We collected data on 28 individual snakes, 13 adults and 15 juveniles. There was no overlap in the size and weight ranges of our adult and juvenile snakes. Adult snakes averaged $52 \pm 4 \mathrm{~cm}$ (range $47-58 \mathrm{~cm}$ ) total length (snout to basal rattle segment), and weighed $104 \pm 31 \mathrm{~g}$ (range 75-174 g). Juveniles were all born the previous fall. Individuals that we were able to measure $(\mathrm{n}=8)$ were $29 \pm 3 \mathrm{~cm}$ (range $25-33 \mathrm{~cm})$ total length, and weighed $23 \pm 8 \mathrm{~g}$ (range 12-35 g). We followed juveniles for 1-8 days (average $=3.1 \pm 2.1$ days) before losing their tracks. Individual telemetered adults were video recorded for 211 days (average $4.6 \pm 3.1$ days). In total, we recorded snakes at ambush sites for $998 \mathrm{~h}$ (517 $\mathrm{h}$ for juveniles and $481 \mathrm{~h}$ for adults). Most individuals were on the surface only during the night and early morning, resulting in a total of $783 \mathrm{~h}$ of nocturnal recordings $(402 \mathrm{~h}$ juveniles, $381 \mathrm{~h}$ adults) and $215 \mathrm{~h}$ of diurnal recordings (115 h juveniles, $100 \mathrm{~h}$ adults). These videos were spread relatively evenly across individuals, with no one individual accounting for more than $10 \%$ of total observation hours.

\subsection{Activity cycles and movements}

Both adult and juvenile sidewinders exhibited a generalized mobile ambush foraging behavior typical of other Crotalus spp. (Clark, 2006; Barbour and Clark, 2012a; Putman et al., 2016), wherein individuals hunted via sit-and-wait ambush at a site for prolonged periods, interspersed with long-distance movements between sites (see Video 1 in Table 1; videos also available in the supplementary online Appendix). Snakes at our site, which were all monitored during the hotter summer months (May-August), sought refuge during 
the day, almost always in lizard or rodent burrows (we could not reliably distinguish between burrow types) and rarely in thick vegetation. When foraging, both adult and juvenile snakes typically emerged from daytime refugia in the evening, exhibited ambush coils and/or movement between ambush sites throughout the night, and ingressed back to burrows in the late morning (Video 2). On 142 occasions ( $n=79$ for juveniles, 63 for adults) we were able to record a complete cycle of circadian activity, from evening emergence to morning ingress. Snakes typically emerged soon after sunset (mean emergence $=20 \pm 69$ min post sunset), and ingressed back into refugia several hours after sunrise (mean ingress $=136 \pm 108 \mathrm{~min}$ post sunrise). Juveniles emerged significantly earlier than adults (adults = $41 \pm 67 \mathrm{~min}$, juveniles $=5 \pm 62 \mathrm{~min}$ post sunset, $\left.\mathrm{F}_{(1,17)}=5.05, p=0.038\right)$, but there was no significant difference between juveniles and adults in ingress time (adults $=112 \pm 128 \mathrm{~min}$, juveniles $=155 \pm 82 \mathrm{~min}$ post sunrise, $\mathrm{F}_{(1,23)}=1.14, p=0.29$ ) (Fig. 1).

Following emergence, snakes typically either adopted a stereotyped ambush coil in the vicinity of their retreat burrow, or began the process of chemosensory-based searching through the environment for a new ambush site. Snakes that adopted ambush coils near retreat burrows were often continuing a period of residence at that site that had begun on a previous day: $60 \%$ of ambush bouts lasted longer than 1 night. Time spent at a site before abandoning to search out a new site ranged from 5 to $246 \mathrm{~h}$, with an average site residence time of $52 \pm 55 \mathrm{~h}$. Adults and juveniles did not differ in their site residence time (adults = $42 \pm 54 \mathrm{~h}$, juveniles $=62 \pm 55 \mathrm{~h}, \mathrm{~F}_{(1,17)}=2.33, p=0.15, \mathrm{n}=29$ for adults, 20 for juveniles) Although we only occasionally observed snakes moving between sites, our limited observations indicated snakes moved via sidewinding locomotion at a rate of approximately 2-4 m per minute, paused frequently, changed directions often, and spent long periods of time tongue flicking air and substrate while moving. We estimated that snakes actively searching for a new ambush site spent, on average, $100 \pm 45$ min searching before adopting an ambush coil or entering a refuge burrow. This estimate did not differ between adults and juveniles (adults, $87 \pm 25 \mathrm{~min}, n=22$; juveniles, $137 \pm 73 \mathrm{~min}, n=7$; $\left.\mathrm{F}_{(1,12)}=3.02, p=0.11\right)$.

The distance between consecutive ambush sites (defined as sites $>3 \mathrm{~m}$ from last ambush coil) was highly variable, ranging from 3 to $683 \mathrm{~m}$, with a mean of $77 \pm 99 \mathrm{~m}$. Although we 
have limited data on juveniles, our estimates indicate that adults and juveniles did not differ in the distance moved between ambush sites (adults, $77 \pm 100 \mathrm{~m}, n=296$; juveniles, $\left.67 \pm 73 \mathrm{~m}, n=12 ; \mathrm{F}_{(1,104)}=0.02, p=0.88\right)$.

\subsection{Ambush behaviors}

While sitting and waiting in ambush, snakes mostly remained motionless but occasionally exhibited chemosensory probing and mouth gaping during nighttime hours. Snakes were rarely seen to probe or mouth gape when coiled during daytime (Video 2). Our random subsample of ambush coils for quantifying probing and mouth gaping resulted in $305 \mathrm{~h}$ of nocturnal foraging and $81 \mathrm{~h}$ of diurnal foraging from 7 adults and 7 juveniles (121 nocturnal, 32 diurnal hours for juveniles; 184 nocturnal, 47 diurnal hours for adults). The average rate of chemosensory probing was $1.5 \pm 1.1$ probes per hour during the night, and $0.02 \pm 0.05$ probes per hour during the day. Snakes exhibited $0.2 \pm 0.4$ mouth gapes per hour during the night, and were not seen to mouth gape during the day. Rates of nocturnal probing did not differ between adults and juveniles (adults $=1.6 \pm 1.1$, juveniles $=1.9 \pm 1.0$, $\left.\mathrm{F}_{(1,9)}=2.37, p=0.16\right)$. Mouth gaping and diurnal probing were too rare to analyze differences statistically.

We recorded 27 bouts of non-rattling tail undulation that lasted between 0.25 and $61 \mathrm{~min}$ (average $=9 \pm 14.5 \mathrm{~min}$ ). Only 6 of 15 juveniles and 2 of 13 adults were seen to undulate (Video 3). Juveniles were significantly more likely to undulate than adults $\left(\chi^{2}=17.9, \mathrm{df}=1\right.$, $p<0.001$ ), and the incidence of tail undulation was not evenly distributed across individual juveniles $\left(\chi^{2}=71.6, \mathrm{df}=14, p<0.001\right)$. Juveniles exhibited undulations 19 times during daylight and six times during the night; undulations were significantly more likely to occur during daylight hours ( $\chi^{2}=41.3, \mathrm{df}=1, p<0.001$ ) (Fig. 2). One adult undulated at night, and the other during daylight. Undulations were never observed to be associated with the presence of potential prey. However, 12 of the 27 undulation bouts occurred within 1 min of snakes abandoning their ambush coil; two additional bouts occurred within 10 min of abandonment. The remaining 13 bouts were not associated with abandonment.

\subsection{Prey encounters and strike behavior}


We recorded 36 prey encounters ( 25 for adults, 11 for juveniles). 29 of the 36 prey encounters were during daytime hours, despite the fact that snakes spent more time foraging at night than during the day. Most daytime encounters (25 of 29) took place in the morning hours, between sunrise and coil abandonment. Prey were encountered during daytime far more frequently than at nighttime $\left(\chi^{2}=73.6, \mathrm{df}=1, p<0.001\right)$. Furthermore, adults encountered prey more frequently during daytime than expected compared to juvenile snakes (19 of 29 daytime encounters involving adults, $\chi^{2}=4.2, \mathrm{df}=1, p=0.041$ ) (Fig. 3). Adults also tended to encounter prey more frequently during nighttime than expected compared to juveniles, but our sample size of nighttime prey encounters was low and this comparison was not statistically significant ( 6 of 7 nighttime encounters involving adults, exact binomial goodness of fit test, $p=0.06$ ).

Of the 36 prey encounters, 26 were lizards and 10 were rodents. Adults and juveniles did not differ in their encounter rate with these two prey types ( $\left.\chi^{2}=0.52, \mathrm{df}=1, p=0.47\right) .21$ of the 36 prey encountered came within strike range (Table 2), and snakes attempted to strike 16 of these 21 prey items (see Videos 4 and 5). Snakes appeared to successfully envenomate prey during 8 of the 16 attempted strikes (see Videos 6 and 7). Adults were successful in 4 of their 10 strike attempts, and juveniles were successful in 4 of their 6 attempts; strike success rate did not differ significantly based on age (likelihood ratio test on $1 \mathrm{df}=0.95, \mathrm{n}=16, \mathrm{p}=0.33$ ).

To examine the effect of distance on strike outcome we first estimated the precision of using snake head length as a size scale by having 10 individuals independently calculate pixel per $\mathrm{cm}$ values from ImageJ for five randomly selected scale frames. The 95\% CIs for these estimates were $\pm 1.66,1.48,1.14,2.61$, and 3.13 pixels per $\mathrm{cm}$. These CIs corresponded to an interval of less than $5 \mathrm{~cm}$ up to a distance of $30.1 \mathrm{~cm}$ for the least precise estimate. Thus, given that we rounded distance estimates to the nearest $5 \mathrm{~cm}$, we are confident that our estimates of distance are reasonably precise up to $25 \mathrm{~cm}$, which was the furthest distance we recorded between predator and prey prior to a strike attempt. Prey was an average of $8 \pm 6 \mathrm{~cm}$ from snakes that struck successfully, compared to $14 \pm 10$ $\mathrm{cm}$ from snakes that missed strikes, but this difference was not significant (likelihood ratio test on $1 \mathrm{df}=1.68, \mathrm{n}=15, \mathrm{p}=0.19$ ). Similarly, strike distance did not differ between adults 
and juveniles (likelihood ratio test on $1 \mathrm{df}=0.95, \mathrm{n}=16, \mathrm{p}=0.33$ ). Prey exhibited dodge maneuvers in 4 of 7 missed strikes, and in none of 7 successful strikes (cf. Table 2), a difference that was significant (likelihood ratio test on $1 \mathrm{df}=5.17, \mathrm{n}=14, \mathrm{p}=0.02$ ). Both adults and juveniles always exhibited high-speed strike movements too rapid to be adequately measured at $15 \mathrm{fps}$. All strike extension times took place within 2 video frames, and all prey contact times where prey was released immediately following envenomation took place within 3 video frames. After 3 of the 8 successful strikes (38\%) snakes held on to prey until it was immobile rather than releasing it; one adult held a small nocturnal mammal (likely a pocket mouse, Perognathus spp.), another adult held a small lizard, and a juvenile also held a small lizard. Snakes released prey and exhibited SICS following the other 5 successful strikes (all towards lizards). Based on visual inspection of individuals, two adults and one juvenile that struck large lizards (two whiptail lizards, Aspidoscelis tigris, and one leopard lizard, Gambelia wislizenii) were known to have recovered and swallowed these prey items within $12 \mathrm{~h}$. The juvenile that swallowed the whiptail lizard was weighed following ingestion, and weighed $15 \mathrm{~g}$ more than 12 days prior. Her initial weight was $30 \mathrm{~g}$, indicating that this meal comprised approximately $50 \%$ of her own body mass. In one of the remaining cases of SICS, a juvenile that had struck a whiptail lizard in the morning was observed for the next two days ambush hunting, with no visible meal bulge, so we assumed the lizard was not recovered following envenomation. The last case involved a juvenile striking a small lizard (likely a Uta stansburiana), but the presence of a new meal bulge was ambiguous.

\section{Discussion}

The general foraging behavior of free-ranging sidewinder rattlesnakes (C. cerastes) in our study was very similar to that of other rattlesnakes (Reinert et al., 1984; Clark, 2006; Barbour and Clark, 2012a; Clark et al., 2012; Putman et al., 2016), including other populations of $C$. cerastes (Brown and Lillywhite, 1992; Secor, 1994). Sidewinders exhibit a general pattern of mobile ambushing that characterizes many pitvipers, with long periods of coiled sitting and waiting in ambush punctuated by relatively short searching movements between ambush sites. Sidewinders rely on a rapid envenomating strike to kill and immobilize prey that come within strike range, and often release struggling prey, 
which is then relocated via chemosensory searching. As with other rattlesnake species, sidewinder strikes are only successful about half the time, and missed strikes frequently are the result of evasive maneuvers by prey (Clark et al., 2012; Putman and Clark, 2015a). Additionally, sidewinders feed both day and night, although they have a more pronounced summer diel cycle than do Crotalus ruber, Crotalus oreganus, or Crotalus horridus, most likely due to the temperature extremes of their environment (Barbour and Clark, 2012a; Clark, 2006; Clark et al., 2012).

Our results show that juveniles in their first summer exhibit very similar movement, activity, and hunting behaviors as adults. Juveniles adopted the general pattern of mobile ambushing characteristic of adults of various Crotalus species and other pitvipers. Adults and juveniles exhibited similar ambush site residence times, movement times, and distances between sites. They also exhibited similar rates of chemosensory probing while coiled and behaved similarly toward potential prey, with no age-based differences in types of prey encountered, strike speed, or strike success. These patterns complement laboratory studies that indicate juvenile and adult $C$. viridis exhibit broadly similar prey striking and handling behavior (Hayes, 1991). In contrast, some other rattlesnake juveniles may adopt different foraging tactics than adults, including the selection of arboreal ambush sites (Rudolph et al., 2004; Figueroa et al., 2008; Gibson et al., 2008).

It is clear that rattlesnakes, like many precocial species, are born with a full suite of predatory behaviors that allow them to effectively capture prey without prior experience. Laboratory studies on a variety of snake species have shown that newborn snakes exhibit innate chemosensory recognition of prey chemical cues (Burghardt, 1967; 1969; Clark, 2004a), can effectively strike and envenomate prey and follow chemical trails left by those prey (Scudder et al., 1992), recognize and exhibit species-typical responses to predators (Weldon and Burghardt, 1979), and exhibit species-typical aggressive mimicry (caudal luring) (Reiserer and Schuett, 2008). However, a variety of studies have also shown that snakes modify their predatory behavior based on experience (Arnold, 1978; Waters and Burghardt, 2005; Mehta, 2008), including rattlesnakes (Clark, 2004b). Thus, it is likely that at least some aspects of predatory behavior might improve with age in the wild. In our study, adults and juveniles appeared to differ in three important aspects of their hunting behavior: (i) adult encounter rates with prey were significantly higher, (ii) only juveniles 
regularly exhibited non-rattling tail undulation while in ambush coils, and (iii) juveniles tended to emerge earlier in the evening than adults. We will discuss each of these in turn.

\subsection{Encounter rates}

Both adults and juveniles relied primarily on diurnal lizards as prey, usually encountered in the early morning following a night spent coiled on the surface. However, both adults and juveniles also encountered and struck at nocturnal small mammals (pocket mice and kangaroo rats), indicating that both nighttime and daytime periods may be important for foraging. Sidewinders almost exclusively move between sites and select ambush locations at night; this behavior may allow them to remain cryptic when ambushing diurnal prey, as they would not need to break crypsis by moving during a time when they are easier to see by visually oriented prey (diurnal lizards). Because individuals were not video recorded constantly when moving and all individuals retreated to burrows during the day (and sometimes night), there is the possibility that some prey encounters could have taken place off camera. However, when we did observe snakes following successful feeding events, we were always able to observe either an obvious food bulge in the gut and/or a significant period of postprandial digestion where individuals remained underground for several days. We did not observe either of these in individuals that had not been actively foraging on the surface, leading us to believe that most prey encounters do not occur in burrows. Nevertheless, our encounter rates should be taken as estimates subject to some imprecision stemming from the inability to record individuals at all times of day and night. Although our sample size for prey encounters is relatively small, adults encountered diurnal prey significantly more frequently than juveniles, and also tended to encounter nocturnal prey more frequently than juveniles. Both adults and juveniles struck at prey that came within range, and strike speed and strike success were similar; in fact, juveniles were successful more often than adults, although the difference was not statistically significant. Thus, if there is an aspect of this general predatory behavior that improves with age and experience, it may be in the selection of ambush sites that lead to higher rates of prey encounters.

There are many aspects of ambush site selection behavior that could differ between snakes, and empirical research would be needed to address these possibilities. Past research has 
shown that rattlesnakes rely extensively on prey-derived chemosensory cues when selecting sites (Duvall et al., 1990; Roth et al., 1999; Theodoratus and Chiszar, 2000; Clark, 2004a), and that feeding experience can alter the way rattlesnakes respond to these chemical cues (Clark, 2004b). Thus, snakes may get better at using chemical cues to assess potential ambush sites as they gain foraging experience.

Alternatively, adults could be making themselves less conspicuous to prey, leading to higher rates of encounters because prey are not actively avoiding ambush sites. Glaudas and Rodríguez-Robles (2011) found evidence of active avoidance of ambushing speckled rattlesnakes (Crotalus mitchelli) by small mammals, which underscores the importance of their crypsis for successful ambush predation. Although we did not quantify specific microhabitat characteristics of ambush sites, adults and juveniles selected qualitatively similar sites, coiling in the vicinity of active lizard or small mammal burrows at the edge of patches of vegetation. All individuals also exhibited a strong tendency to "crater" in the sand (Video 2), shifting their coils in a manner that pushed them slightly below the sand surface, presumably making them more difficult to see (Brown and Lillywhite, 1992; Secor, 1994). However, it is possible that adult sidewinders exhibited some other subtle movements and/or positioning not apparent to human observers that made them less conspicuous than juveniles.

Finally, although the difference in prey encounter rates between juveniles and adults may imply improvement with experience or learning, age-based differences in mortality could also explain this pattern. That is, juveniles that chose less effective ambush sites would be expected to exhibit higher mortality rates, leading to an adult age class that contained more effective ambush hunters. This possibility should be investigated, given the general higher rates of mortality associated with juvenile life stages of other rattlesnake species (Diller and Wallace, 2002; Brown et al., 2007). Such an investigation would require tracking the behavior and survival of a large cohort of juveniles over time.

\subsection{Tail undulation}

Although both adults and juveniles exhibited similar rates of chemosensory probing and mouth gaping while coiled in ambush, only juveniles were regularly seen to exhibit nonrattling tail undulation, and only some juveniles engaged in this behavior. Although this 
behavior resembled caudal luring (sensu Heatwole and Davison, 1976), somewhat puzzlingly, it was never seen in association with the presence of prey items (lizards or small mammals). Past studies have revealed that juveniles (but rarely adults) of many viper species engage in caudal luring (Heatwole and Davison, 1976; Reiserer, 2002; Rabatsky and Waterman, 2005a), but caudal luring in juvenile vipers, including sidewinders, is stimulated by the presence of lizards and inhibited by the presence of larger non-prey animals (Reiserer and Schuett, 2008).

Because the caudal-luring-like tail undulations we observed were never seen to be associated with the presence of lizards, it is unclear what, if any, function this behavior may serve. Although caudal luring has been investigated in several species in captivity, to our knowledge, this is the first quantitative report of viperid tail undulation in the field. Several aspects of this behavior are unexpected and may be deserving of additional experimental scrutiny. First, tail undulations were strongly dependent on snake identity, exhibited frequently by some individuals and never by others. Specifically, 3 of 15 juveniles undulated repeatedly at multiple different sites and days, 3 other juveniles exhibited occasional undulations, and the other 11 juveniles were not seen to exhibit this behavior at all, despite the fact that many of them were recorded for multiple days and at multiple sites. Interestingly, in their empirical investigation, Reiserer and Schuett (2008) also documented strong inter-individual differences in caudal luring. Their analysis included 40 juveniles captive-raised from three litters, two from the Sonoran Desert of Arizona, and one from the Colorado Desert of California. Only 2 of the 11 juveniles from the California litter exhibited caudal luring whereas 20 of the 29 Arizona snakes did so. Our findings on tail undulations corroborate this pattern of strong individual variation, and support the notion that this behavior may be caudal luring (Reiserer and Schuett, 2008). Although the tail undulation we observed in situ was never seen to attract lizards, or stimulated by their presence, it still may represent unsuccessful attempts to lure prey. Although in most studies of caudal luring in captivity snakes are mainly reported to caudal lure only when presented with appropriate prey (e.g., Rabatsky and Waterman, 2005a; Reiserer and Schuett, 2008), one study of captive rock rattlesnakes (Crotalus lepidus) indicated frequent luring in the absence of prey (Kauffeld, 1943). Caudal luring has been shown repeatedly to be attractive to prey under captive conditions, but no studies we are 
aware of have attempted to demonstrate its efficacy under field conditions. Although we did not observe tail undulations attracting prey, our field observations also showed that $C$. cerastes encounter prey infrequently under natural conditions, and successfully attack prey during less than half of all encounters. Thus, even if these tail undulations attracted prey only occasionally, the overall impact on predation success rate could be substantial. The tail undulations we observed were also peculiar in terms of timing with respect to abandonment of ambush coils. Over half of tail undulations took place immediately before the snake abandoned its ambush coil and moved out of the frame of the camera. This timing does not suggest a caudal luring function. We would expect snakes exhibiting caudal luring to remain coiled until approached by prey, rather than lure and then approach prey themselves. It is possible that snakes were luring because they sensed the presence of relatively distant prey (out of the field of view of the camera, typically $\sim 2 \mathrm{~m}$ ), and then abandoned their coil to move closer to the vicinity of prey activity when prey did not approach. Although laboratory studies have not reported snakes moving out of their ambush coils following ineffective luring, these studies all appear to present prey in close proximity, negating the ability of the snakes to respond to more distant prey.

It may be that the tail undulations we observed serve some function other than luring, but the context and form of the undulations we observed do not align with any other known function for snake tail movements. Non-rattling defensive tail movements occur in pygmy rattlesnakes (Rabatsky and Waterman, 2005b), and various viperid species exhibit tail undulations during conspecific interactions (Carpenter, 1977; Gillingham et al., 1983; Hayes, 1986; Putman and Clark, 2015b; Schuett, 1997). The tail undulations we observed were not associated with conspecifics or the presence of potential predators. Although our video resolution was generally not fine enough for us to quantify specific variables associated with tail movement, qualitatively the behavior did not match the description of pygmy rattlesnake defensive displays given by Rabatsky and Waterman (2005b). Clearly further research is necessary to understand the function of non-rattling tail undulations under natural conditions.

\subsection{Emergence time}


The final statistical difference between juvenile and adult behavior was in emergence time. Juveniles emerged, on average, a few minutes prior to sunset, whereas adults emerged 40 minutes after. Juveniles also tended to stay out longer in the morning than adults but this difference was not significant. Although both adults and juveniles are mainly nocturnal, our data indicate that juveniles are slightly more active in daylight hours. This may be due to a greater reliance on lizards over small mammals as prey, as most desert lizards are exclusively diurnal and most desert small mammals are exclusively nocturnal. Published dietary information on $C$. cerastes indicates that, like many rattlesnakes, this species undergoes an ontogenetic shift in diet toward an increased reliance on small mammals over lizards (Klauber, 1944; Funk, 1965), a pattern that has been reported for a wide variety of rattlesnake species (Klauber, 1972; Campbell and Lamar, 2004). Klauber (1944) summarized the relative incidence of lizards and mammals in Mohave desert sidewinder $(C$. cerastes cerastes) by showing that the body length ranges of snakes found with mammals in their stomachs (345-587 mm) included larger individuals than those found with lizards in their stomachs (299-503 mm). Although Funk (1965) also indicated that C. c. laterorepens from Yuma County, Arizona similarly consumed an almost equal number of small mammals and lizards, he did not include a breakdown by snake size or age.

\subsection{Strikes and post-strike behavior}

Although prey encounter rates differed between adults and juveniles, snakes did not exhibit any obvious age-based differences in response to prey that came within strike range. Snakes attempted to strike 16 of 21 prey items that came within strike range. In all five cases where snakes did not attempt to strike prey there appeared to be mitigating factors. Three cases involved small mammals exhibiting anti-snake displays (one desert kangaroo rat, two round-tailed ground squirrels), behaviors that have been shown to decrease the propensity of rattlesnakes to strike (Barbour and Clark, 2012b). The other two cases were lizards that were partially obstructed by thick vegetation during their approach.

Although our sample size is small, juveniles and adults exhibited similar strike behavior. Both struck readily at small mammals and lizards that came within range, were successful in about half of strike attempts, and struck rapidly. Although our videos were not adequate 
for estimating strike speeds precisely, in all cases the extension of the snake from coil to prey contact took place in either one or two camera frames. High-speed videography would be necessary to quantify any biologically significant variation in strike speed, which could take place at a resolution too fine for us to capture with standard video cameras (Putman and Clark, 2015a).

In the present study, both adults and juveniles struck at both lizards and small mammals, although lizards were the predominant prey. However, with a larger sample size a more pronounced difference between adults and juveniles regarding the relative reliance on lizards versus small mammals might be revealed. As discussed above, the general pattern in this species is toward an increasing reliance on small mammals over lizards as prey in larger snakes.

Our limited data on post-strike behavior also shows similar patterns across ages. Five snakes (two adults and three juveniles) released lizards immediately post-strike, and all exhibited stereotypical SICS behavior. Three of these snakes were found to recover prey, one was found not to, and one case was ambiguous. Three snakes (two adults, one juvenile) held on to prey post-strike until it was immobilized, and then ingested the carcass. Previous laboratory studies on SICS indicate that newborn snakes feeding for the first time exhibit SICS following strikes in a manner similar to wild-caught adult rattlesnakes (Scudder et al., 1992).

\subsection{Movements}

Juvenile and adult sidewinders in the present study exhibited similar movement characteristics while foraging: they tended to stay at a site for long periods, exhibit multiple ambush coils over the course of several evenings, and search haphazardly through the environment for several hours after leaving a site before adopting a new site. The distance that they moved between sites was not significantly different. A similar pattern for this species was reported by Secor (1994), who conducted a more extensive analysis on movements at a nearby site in the Mohave desert and found that, with the exception of adult male mate searching movements made during the spring and fall mating periods, juveniles and adults exhibited similar movement behavior in terms of length, frequency, 
direction, and path tortuosity. Both Secor's (1994) study and ours show that sidewinders often move much farther between successive ambush sites than other pitvipers. The amount of time spent moving between sites, and the distance covered, is likely related to prey resources. In similar studies, the average distance between ambush sites was less than $10 \mathrm{~m}$ for C. oreganus foraging in ground squirrel colonies (Putman et al., 2016, which contain a high density of potential prey; $C$. horridus moved an average of $47 \mathrm{~m}$ between sites in relatively productive eastern deciduous forests (Clark, 2006). Sidewinders occupy harsh, low-productivity deserts where prey is likely to be scarce. Their relatively longdistance movements are probably necessary to locate prey-derived chemical cues indicating suitable ambush sites.

\subsection{General conclusions}

Ontogenetic variation in behavior can be a result of either innate developmental changes that represent evolved age-specific adaptations, or behavioral plasticity that allows individuals to modify their behavior with experience ( West et al., 1988; Lima and Dill, 1990). In our study, differences between juveniles and adults associated with tail undulations and activity cycles likely represent age-specific adaptations. Several other studies on snakes have shown that individuals exhibit innate ontogenetic shifts of key traits related to predation, including chemosensory preferences (Mushinsky and Lotz, 1980), foraging strategies and habitat use (Lind and Welsh, 1994; Savitzky and Burghardt, 2000; Eskew et al., 2009), responses to environmental stimuli (Clarke et al., 1996), morphology (Rossman, 1980), venom content (Chippaux et al., 1991; Mackessy et al., 2003), and caudal luring (Neill, 1960; Rabatsky and Waterman, 2005a). These ontogenetic changes are mostly thought to be associated with age-specific prey specialization. Rattlesnakes in general, including sidewinders, typically rely more on lizards as prey as juveniles, shifting to small rodents as adults (Klauber, 1972; Campbell and Lamar, 2004), and the age differences we document in diurnal activity are consistent with this shift.

The greater prey encounter rates experienced by adults, however, probably reflect behavioral plasticity associated with experience. This difference indicates that individual snakes improve either in their ability to assess potential ambush sites, or their ability to remain cryptic while coiled in ambush. Laboratory studies on a variety of species have 
demonstrated that snakes can improve various aspects of their predation behavior with experience (Krause and Burghardt, 2001; Mehta, 2008), including their chemosensory recognition of ambush sites (Clark, 2004b). It is our hope that these natural observations will serve as the foundation for controlled experimental studies that address these hypotheses empirically.

\section{Acknowledgements}

For assistance with fieldwork we thank Erik Jourgensen, Kenneth Huang, Curt Barnes, Trevor Darragh, Tara Easter, Darren Fraser, Mark Herr, Mike Hogan, Erynn Rebol, Steve Hein, Kathlyn Stauffer, Chris Brahm, and Jessica Tingle. For assistance with field logistics, we thank Robert Fulton, Jason Wallace, and the rest of the staff at California State University Desert Studies Center. For assistance with quantifying video data, we thank Feliza Suniga and Eliana Moustakas. Funding for this research was provided by San Diego State University, the National Science Foundation (DBI-0951010 to R.W.C.), the California Desert Research Fund of the Community Foundation (SID 811996543 to S.W.D.), and the Judith Presch Desert Research Scholarship (to B.J.P., 2012; S.W.D., 2013). All methods were approved by the Institutional Animal Care and Use Committee of San Diego State University (APF 10-09-025C).

\section{Appendix A. Supplementary data}

Supplementary data associated with this article can be found in the online version at doi: \#\#\#. 


\section{References}

Abramoff, M.D., Magalhaes, P.J., Ram, S.J., 2004. Image processing with ImageJ. Biophot. Int. $11,36-42$.

Arnold, S.J., 1978. Some effects of early experience on feeding responses in the common garter snake, Thamnophis sirtalis. Anim. Behav. 26, 455-462.

Barbour, M.A., Clark, R.W., 2012a. Diel cycles in chemosensory behaviors of free-ranging rattlesnakes lying in wait for prey. Ethology 118, 480-488.

Barbour, M.A., Clark, R.W., 2012b. Ground squirrel tail-flag displays alter both predatory strike and ambush site selection behaviours of rattlesnakes. Proc. R. Soc. B 279, 38273833.

Brown, T.W., Lillywhite, H.B., 1992. Autecology of the Mojave Desert sidewinder, Crotalus cerastes, at Kelso Dunes, Mojave Desert, California, USA. In: Campbell, J.A., Brodie, E.D.J. (Eds.), Biology of the Pitvipers. Selva Press, Tyler, TX, pp. 279-308.

Brown, W.S., Kery, M., Hines, J.E., 2007. Survival of timber rattlesnakes (Crotalus horridus) estimated by capture-recapture models in relation to age, sex, color morph, time, and birthplace. Copeia 2007, 656-671.

Burghardt, G.M., 1967. Chemical-cue preferences of inexperienced snakes: comparative aspects. Science 157, 718-721.

Burghardt, G.M., 1969. Comparative prey-attack studies in newborn snakes of the genus Thamnophis. Behaviour 33, 77-113.

Campbell, J.A., Lamar, W.W., 2004. The Venomous Reptiles of the Western Hemisphere. Cornell University Press, Ithaca, NY.

Caro, T.M., 1980. Effects of the mother, object play, and adult experience on predation in cats. Behav. Neur. Biol. 29, 29-51.

Carpenter, C.C., 1977. Communication and displays of snakes. Am. Zool. 17, 217-223.

Chippaux, J.P., Williams, V., White, J., 1991. Snake venom variability: methods of study, results and interpretation. Toxicon 29, 1279-1303.

Chiszar, D., Lee, R.K.K., Radcliffe, C.W., Smith, H.M., 1992. Searching behaviors by rattlesnakes following predatory strikes. In: Campbell, J.A., Brodie, E.D.J. (Eds.), Biology of the Pitvipers. Selva Press, Tyler, TX, pp. 369-382.

Clark, R.W., 2004a. Timber rattlesnakes (Crotalus horridus) use chemical cues to select ambush sites. J. Chem. Ecol. 30, 607-617.

Clark, R.W., 2004b. Feeding experience modifies the assessment of ambush sites by the timber rattlesnake, a sit-and-wait predator. Ethology 110, 471-483.

Clark, R.W., 2006. Fixed videography to study predation behavior of an ambush foraging snake, Crotalus horridus. Copeia 2006, 181-187.

Clark, R.W., Tangco, S., Barbour, M.A., 2012. Field video recordings reveal factors influencing predatory strike success of free-ranging rattlesnakes (Crotalus spp.). Anim. Behav. 84, 183-190.

Clarke, J.A., Chopko, J.T., Mackessy, S.P., 1996. The effect of moonlight on activity patterns of adult and juvenile prairie rattlesnakes (Crotalus viridis viridis). J. Herpetol. 30, 192-197.

Clutton-Brock, T.H., 1991. The Evolution of Parental Care. Princeton University Press, Princeton, NJ.

Cresswell, W., Lind, J., Quinn, J.L., 2010. Predator-hunting success and prey vulnerability: quantifying the spatial scale over which lethal and non-lethal effects of predation occur. J. Anim. Ecol. 79, 556-562. 
Croy, M.I., Hughes, R.N., 1991. The role of learning and memory in the feeding behaviour of the fifteen-spined stickleback, Spinachia spinachia L. Anim. Behav. 41, 149-159.

Danchin, E., 2004. Public information: from nosy neighbors to cultural evolution. Science 305, 487-491.

Diller, L.V., Wallace, R.L., 2002. Growth, reproduction, and survival in a population of Crotalus viridis oreganus in north central Idaho. Herpetol. Monogr. 16, 26-45.

Duvall, D., Chiszar, D., Hayes, W.K., Leonhardt, J.K., Goode, M.J., 1990. Chemical and behavioral ecology of foraging in prairie rattlesnakes (Crotalus viridis viridis). J. Chem. Ecol. 16, 87-101.

Eberhard, W.G., 1982. Behavioral characters for the higher classification of orb-weaving spiders. Evolution 36, 1067-1095.

Eskew, E.A., Willson, J.D., Winne, C.T., 2009. Ambush site selection and ontogenetic shifts in foraging strategy in a semi-aquatic pit viper, the Eastern cottonmouth. J. Zool. 277, 179-186.

Ewert, J.P., Burghagen, H., 1979. Ontogenetic aspects on visual "size-constancy" phenomena in the midwife toad Alytes obstetricans (Laur.). Brain Behav. Evol. 16, 99-112.

Fanshawe, J.H., Fitzgibbon, C.D., 1993. Factors influencing the hunting success of an African wild dog pack. Anim. Behav. 45, 479-490.

Figueroa, A., Duban, E.A., Hayes, W.K., 2008. Behavioral ecology of neonate Southern Pacific rattlesnakes (Crotalus oreganus helleri) tracked with externally-attached transmitters. In: Hayes, W.K., Beaman, K.R., Cardwell, M.D., Bush, S.P. (Eds.), Biology of Rattlesnakes. Loma Linda University Press, Loma Linda, CA, pp. 365-376.

Ford, J.K.B., Ellis, G.M., Olesiuk, P.F., Balcomb, K.C., 2010. Linking killer whale survival and prey abundance: food limitation in the oceans' apex predator? Biol. Lett. 6, 139-142.

Funk, R.S., 1965. Food of Crotalus cerastes laterorepens in Yuma County, Arizona. Herpetologica 21, 15-17.

Gibson, S.E., Walker, Z.J., Kingsbury, B.A., 2008. Microhabitat preferences of the timber rattlesnake (Crotalus horridus) in the hardwood forests of Indiana. In: Hayes, W.K., Beaman, K.R., Cardwell, M.D., Bush, S.P. (Eds.), Biology of Rattlesnakes. Loma Linda University Press, Loma Linda, CA, pp. 275-286.

Gillingham, J.C., Carpenter, C.C., Murphy, J.B., 1983. Courtship, male combat and dominance in the western diamondback rattlesnake, Crotalus atrox. J. Herpetol. 17, 265-270.

Glaudas, X., Rodríguez-Robles, J.A., 2011. A two-level problem: habitat selection in relation to prey abundance in an ambush predator, the speckled rattlesnake (Crotalus mitchellii). Behaviour 148, 1491-1524.

Graves, B., Duvall, D., 1983. Occurrence and function of prairie rattlesnake mouth gaping in a non-feeding context. J. Exp. Zool. 227, 471-474.

Hayes, W.K., 1986. Observations of courtship in the rattlesnake, Crotalus viridis oreganus. J. Herpetol. 20, 246-249.

Hayes, W.K., 1991. Ontogeny of striking, prey-handling and envenomation behavior of prairie rattlesnakes (Crotalus v. viridis). Toxicon 29, 867-875.

Heatwole, H., Davison, E., 1976. A review of caudal luring in snakes with notes on its occurrence in the Saharan sand viper, Cerastes vipera. Herpetologica 32, 332-336.

Heiling, A.M., Herberstein, M.E., 1999. The role of experience in web-building spiders (Araneidae). Anim. Cogn. 2, 171-177.

Kauffeld, C.F., 1943. Growth and feeding of newborn Price's and green rock rattlesnakes. 
Am. Midl. Nat. 29, 607-614.

Klauber, L.M., 1944. The sidewinder, Crotalus cerastes, with description of a new subspecies. Trans. San Diego Soc. Nat. Hist. 10, 91-126.

Klauber, L.M., 1972. Rattlesnakes: Their Habits, Life Histories, and Influence on Mankind, $2^{\text {nd }}$ ed. University of California Press, Berkeley, CA.

Krause, M.A., Burghardt, G.M., 2001. Neonatal plasticity and adult foraging behavior in garter snakes (Thamnophis sirtalis) from two nearby, but ecologically dissimilar, habitats. Herpetol. Monogr. 15, 100-123.

Lima, S.L., 2002. Putting predators back into behavioral predator-prey interactions. Trends Ecol. Evol. 17, 70-75.

Lima, S.L., Dill, L.M., 1990. Behavioral decisions made under the risk of predation: a review and prospectus. Can. J. Zool. 68, 619-640.

Lind, A.J., Welsh, H.H., 1994. Ontogenetic changes in foraging behaviour and habitat use by the Oregon garter snake, Thamnophis atratus hydrophilus. Anim. Behav. 48, 1261-1273.

Mackessy, S.P., Williams, K., Ashton, K.G., 2003. Ontogenetic variation in venom composition and diet of Crotalus oreganus concolor: a case of venom paedomorphosis? Copeia 2003, 769-782.

Mehta, R.S., 2008. Early experience shapes the development of behavioral repertoires of hatchling snakes. J. Ethol. 27, 143-151.

Mushinsky, H.R., Lotz, K.H., 1980. Chemoreceptive responses of two sympatric water snakes to extracts of commonly ingested prey species. J. Chem. Ecol. 6, 523-535.

Neill, W.T., 1960. The caudal lure of various juvenile snakes. Quart. J. Florida Acad. Sci. 23, $173-200$.

Putman, B.J., Clark, R.W., 2015a. The fear of unseen predators: ground squirrel tail flagging in the absence of snakes signals vigilance. Behav. Ecol. 26, 185-193.

Putman, B.J., Clark, R.W., 2015b. Crotalus oreganus (Northern Pacific rattlesnake): nonrattling tail display. Herpetol. Rev. 46, 269-270.

Putman, B.J., Barbour, M.A., Clark, R.W., 2016. The foraging behavior of free-ranging rattlesnakes (Crotalus oreganus) in California ground squirrel (Otospermophilus beecheyi) colonies. Herpetologica 72, 55-63.

R Development Core Team, 2011. R: A Language and Environment for Statistical Computing. The R Foundation for Statistical Computing, Vienna, Austria. http://www.Rproject.org/.

Rabatsky, A.M., Waterman, J.M., 2005a. Ontogenetic shifts and sex differences in caudal luring in the dusky pygmy rattlesnake, Sistrurus miliarius barbouri. Herpetologica 61, 87-91.

Rabatsky, A.M., Waterman, J.M., 2005b. Non-rattling defensive tail display in the dusky pygmy rattlesnake, Sistrurus miliarius barbouri: a previously undescribed behavior. Herpetol. Rev. 36, 236-238.

Reinert, H.K., Cundall, D., 1982. An improved surgical implantation method for radiotracking snakes. Copeia 1982, 702-705.

Reinert, H.K., Cundall, D., Bushar, L.M., 1984. Foraging behavior of the timber rattlesnake, Crotalus horridus. Copeia 1984, 976-981.

Reinert, H.K., Reinert, H.K., Macgregor, G.A., Bushar, L.M., Zappalorti, R.T., 2011. Foraging ecology of timber rattlesnakes, Crotalus horridus. Copeia 2011, 430-442.

Reiserer, R.S., 2002. Stimulus control of caudal luring and other feeding responses: a 
program for research on visual perception in vipers. In: Schuett, G.W., Hoggren, M., Douglas, M.E. (Eds.), Biology of the Vipers. Eagle Mountain Publishing, Eagle Mountain, UT, pp. 361-384.

Reiserer, R.S., Schuett, G.W., 2008. Aggressive mimicry in neonates of the sidewinder rattlesnake, Crotalus cerastes (Serpentes: Viperidae): stimulus control and visual perception of prey luring. Biol. J. Linn. Soc. 95, 81-91.

Robbins, T.R., Langkilde, T., 2012. The consequences of lifetime and evolutionary exposure to toxic prey: changes in avoidance behaviour through ontogeny. J. Evol. Biol. 25, 19371946.

Rossman, C.E., 1980. Ontogenetic changes in skull proportions of the diamondback water snake, Nerodia rhombifera. Herpetologica 36, 42-46.

Roth, E.D., May, P.G., Farrell, T.M., 1999. Pigmy rattlesnakes use frog-derived chemical cues to select foraging sites. Copeia 1999, 772-774.

Rudolph, D.C., Schaefer, R.R., Saenz, D., Conner, R.N., 2004. Arboreal behavior in the timber rattlesnake, Crotalus horridus, in eastern Texas. Texas J. Sci. 56, 395-404.

Savitzky, B.A., Burghardt, G.M., 2000. Ontogeny of predatory behavior in the aquatic specialist snake, Nerodia rhombifer, during the first year of life. Herpetol. Monogr. 14, 401-419.

Schuett, G.W., 1997. Body size and agonistic experience affect dominance and mating success in male copperheads. Anim. Behav. 54, 213-224.

Scudder, K.M., Chiszar, D., Smith, H.M., 1992. Strike-induced chemosensory searching and trailing behaviour in neonatal rattlesnakes. Anim. Behav. 44, 574-576.

Secor, S.M., 1994. Ecological significance of movements and activity range for the sidewinder, Crotalus cerastes. Copeia 1994, 631-645.

Taylor, E.N., Malawy, M.A., Browning, D.M., Lemar, S.V., DeNardo, D.F., 2005. Effects of food supplementation on the physiological ecology of female Western diamond-backed rattlesnakes (Crotalus atrox). Oecologia 144, 206-213.

Theodoratus, D.H., Chiszar, D., 2000. Habitat selection and prey odor in the foraging behavior of western rattlesnakes (Crotalus viridis). Behaviour 137, 119-135.

Thornton, A., McAuliffe, K., 2006. Teaching in wild meerkats. Science 313, 227-229.

Újvári, B., Korsós, Z., 2000. Use of radiotelemetry on snakes: a review. Acta Zool. Acad. Sci. Hung. 46, 115-146.

Waters, R.M., Burghardt, G.M., 2005. The interaction of food motivation and experience in the ontogeny of chemoreception in crayfish snakes. Anim. Behav. 69, 363-374.

Weldon, P.J., Burghardt, G.M., 1979. The ophiophage defensive response in crotaline snakes: extension to new taxa. J. Chem. Ecol. 5, 141-151.

West, M.J., King, A.P., Arberg, A.A., 1988. The inheritance of niches: the role of ecological legacies in ontogeny. In: Blass, E.M. (Ed.), Handbook of Behavioral Neurobiology, vol. 9. Plenum Press, New York, pp. 41-62.

Wiehn, J., Korpimäki, E., 1997. Food limitation on brood size: experimental evidence in the Eurasian kestrel. Ecology 78, 2043-2050. 


\section{Figure captions}

Fig. 1. Emergence and ingress times of adult and juvenile snakes. All emergence times are shown relative to sunset (left side of axis) and all ingress times are shown relative to sunrise (right side of axis) on the day of the event.

Fig. 2. The relative timing and number of observed bouts of tail undulation for juveniles and adults. All times are shown relative to either sunset (left side of axis) or sunrise (right side of axis) on the day of the event.

Fig. 3. Observed and expected number of daytime prey encounters for juvenile and adult snakes. The daytime prey encounter rate was significantly greater for adults than for juveniles. 
Table 1

Video files referenced in the text that illustrate species-typical sidewinder behavior. Videos are viewable through the video-sharing site YouTube (or see the supplementary online Appendix).

\begin{tabular}{|c|c|c|}
\hline Video & URL & Description \\
\hline Video 1 & http://youtu.be/AmGn3eESJkg & $\begin{array}{l}\text { Sidewinding locomotion typical of snakes moving during active } \\
\text { search phase }\end{array}$ \\
\hline Video 2 & http://youtu.be/pPF0Wupl31E & $\begin{array}{l}\text { Time lapse video of adult exhibiting species-typical behaviors } \\
\text { while in sit-and-wait phase of ambush behavior }\end{array}$ \\
\hline Video 3 & http://youtu.be/N2Nf8uMOZ2c & Nocturnal tail undulation behavior of adult snake \\
\hline Video 4 & http://youtu.be/J18Ma7GMLks & $\begin{array}{l}\text { Adult snake misses strike attempt toward whiptail lizard, which } \\
\text { exhibits dodge maneuver }\end{array}$ \\
\hline Video 5 & http://youtu.be/epwYN9qp2TI & $\begin{array}{l}\text { Juvenile snake misses strike attempt toward Merriam's kangaroo } \\
\text { rat, which exhibits dodge maneuver }\end{array}$ \\
\hline Video 6 & http://youtu.be/hREihZCiCd8 & $\begin{array}{l}\text { Juvenile snake successfully strikes whiptail lizard, begins strike- } \\
\text { induced chemosensory searching after releasing lizard }\end{array}$ \\
\hline Video 7 & http://youtu.be/BLLoYSz7DiI & $\begin{array}{l}\text { Adult snake successfully strikes small nocturnal rodent, holds } \\
\text { until prey is immobile, ingests carcass, and resumes ambush coil }\end{array}$ \\
\hline
\end{tabular}


Table 2

Summary of data from recordings of free-ranging sidewinder rattlesnakes, Crotalus cerastes, responding to prey that came within strike range. Dash symbol indicates data are missing, and NA indicates value is not applicable. Dist = proximity between snake and prey in cm; Strike = snake response to prey as either successful strike (hit), attempted strike that missed (miss), or did not attempt strike (no strike); Dodge = prey exhibited dodge maneuver (yes) or did not (no); Held = snake held on to prey until it was immobile (yes) or released after strike (no). 


\begin{tabular}{|c|c|c|c|c|c|c|c|c|c|}
\hline Time & Snake & Age & Prey type & Prey sp. & Dist & Strike & Dodge & Held & Notes \\
\hline $20: 15$ & A4 & adult & lizard & $\begin{array}{l}\text { Gambelia } \\
\text { wislizenii }\end{array}$ & - & hit & - & no & $\begin{array}{l}\text { Strike occurred out of frame of video, but recording } \\
\text { documented SICS and ingestion of prey }\end{array}$ \\
\hline $8: 26$ & A6 & adult & lizard & $\begin{array}{l}\text { Aspidoscelis } \\
\text { tigris }\end{array}$ & 20 & hit & no & no & $\begin{array}{l}\text { Snake remains immobile for } 95 \mathrm{~s} \text { after strike before } \\
\text { beginning SICS }\end{array}$ \\
\hline 9:07 & A7 & adult & lizard & $\begin{array}{l}\text { unidentified } \\
\text { lizard }\end{array}$ & 5 & hit & no & yes & $\begin{array}{l}\text { Poor video quality prevented quantification of } \\
\text { extend and contact time }\end{array}$ \\
\hline 0:19 & A8 & adult & mammal & $\begin{array}{l}\text { unidentified } \\
\text { mammal }\end{array}$ & 10 & hit & no & yes & $\begin{array}{l}\text { Small nocturnal rodent, likely Perognathus } \\
\text { longimembris, struck, held, and ingested }\end{array}$ \\
\hline 8:07 & $\mathrm{J} 2$ & juvenile & lizard & $\begin{array}{l}\text { Aspidoscelis } \\
\text { tigris }\end{array}$ & 5 & hit & no & no & $\begin{array}{l}\text { Snake remains immobile for } 20 \mathrm{~s} \text { after strike before } \\
\text { beginning SICS }\end{array}$ \\
\hline 8:37 & $\mathrm{J} 3$ & juvenile & lizard & $\begin{array}{l}\text { unidentified } \\
\text { lizard }\end{array}$ & 5 & hit & no & no & $\begin{array}{l}\text { Snake remains immobile for } 130 \mathrm{~s} \text { after strike } \\
\text { before beginning SICS }\end{array}$ \\
\hline 6:03 & $\mathrm{J} 4$ & juvenile & lizard & $\begin{array}{l}\text { unidentified } \\
\text { lizard }\end{array}$ & 5 & hit & no & yes & $\begin{array}{l}\text { Small lizard, likely Uta stansburiana, is struck, } \\
\text { held, and ingested }\end{array}$ \\
\hline $8: 32$ & $\mathrm{~J} 5$ & juvenile & lizard & $\begin{array}{l}\text { Aspidoscelis } \\
\text { tigris }\end{array}$ & 5 & hit & no & no & $\begin{array}{l}\text { Snake remains immobile for } 27 \mathrm{~s} \text { after strike before } \\
\text { beginning SICS }\end{array}$ \\
\hline $8: 15$ & A1 & adult & lizard & $\begin{array}{l}\text { Aspidoscelis } \\
\text { tigris }\end{array}$ & 25 & miss & no & NA & Adult Aspidoscelis tigris \\
\hline $10: 28$ & A2 & adult & lizard & $\begin{array}{l}\text { unidentified } \\
\text { lizard }\end{array}$ & 5 & miss & yes & NA & Lizard is likely Urosaurus graciosus \\
\hline 0:06 & A3 & adult & mammal & $\begin{array}{l}\text { Dipodomys } \\
\text { merriami }\end{array}$ & 15 & miss & no & NA & Adult Dipodomys merriami \\
\hline $6: 16$ & A4 & adult & lizard & $\begin{array}{l}\text { unidentified } \\
\text { lizard }\end{array}$ & 10 & miss & - & NA & $\begin{array}{l}\text { Lizard is likely Uta stansburiana; poor video } \\
\text { quality prevent quantification of extend/dodge }\end{array}$ \\
\hline $7: 52$ & A4 & adult & lizard & $\begin{array}{l}\text { Aspidoscelis } \\
\text { tigris }\end{array}$ & 25 & miss & yes & NA & Adult Aspidoscelis tigris \\
\hline $5: 31$ & A5 & adult & lizard & $\begin{array}{l}\text { unidentified } \\
\text { lizard }\end{array}$ & 5 & miss & no & NA & Lizard is likely Uta stansburiana \\
\hline $0: 52$ & $\mathrm{~J} 1$ & juvenile & mammal & $\begin{array}{l}\text { Dipodomys } \\
\text { merriami }\end{array}$ & 5 & miss & yes & NA & Adult Dipodomys merriami \\
\hline $6: 57$ & $\mathrm{~J} 2$ & juvenile & lizard & $\begin{array}{l}\text { unidentified } \\
\text { lizard }\end{array}$ & 15 & miss & yes & NA & Lizard is likely Uta stansburiana \\
\hline $20: 13$ & A9 & adult & mammal & $\begin{array}{l}\text { Dipodomys } \\
\text { deserti }\end{array}$ & 10 & no strike & - & - & $\begin{array}{l}\text { Adult Dipodomys deserti engages in extensive anti- } \\
\text { snake signaling displays }\end{array}$ \\
\hline $7: 52$ & A2 & adult & mammal & $\begin{array}{l}\text { Xerospermophilus } \\
\text { tereticaudus }\end{array}$ & 20 & no strike & - & - & $\begin{array}{l}\text { Adult Xerospermophilus tereticaudus engages in } \\
\text { extensive anti-snake signaling displays }\end{array}$ \\
\hline 8:09 & A2 & adult & mammal & $\begin{array}{l}\text { Xerospermophilus } \\
\text { tereticaudus }\end{array}$ & 20 & no strike & - & - & $\begin{array}{l}\text { Adult Xerospermophilus tereticaudus engages in } \\
\text { extensive anti-snake signaling displays }\end{array}$ \\
\hline $9: 38$ & $\mathrm{~A} 2$ & adult & lizard & $\begin{array}{l}\text { unidentified } \\
\text { lizard }\end{array}$ & 15 & no strike & - & - & $\begin{array}{l}\text { Lizard likely Urosaurus graciosus; vegetation in } \\
\text { between lizard and snake may have prevented strike }\end{array}$ \\
\hline $19: 21$ & A7 & adult & lizard & $\begin{array}{l}\text { unidentified } \\
\text { lizard }\end{array}$ & 5 & no strike & - & - & $\begin{array}{l}\text { Lizard likely Uta stansburiana; vegetation in } \\
\text { between lizard and snake may have prevented strike }\end{array}$ \\
\hline
\end{tabular}




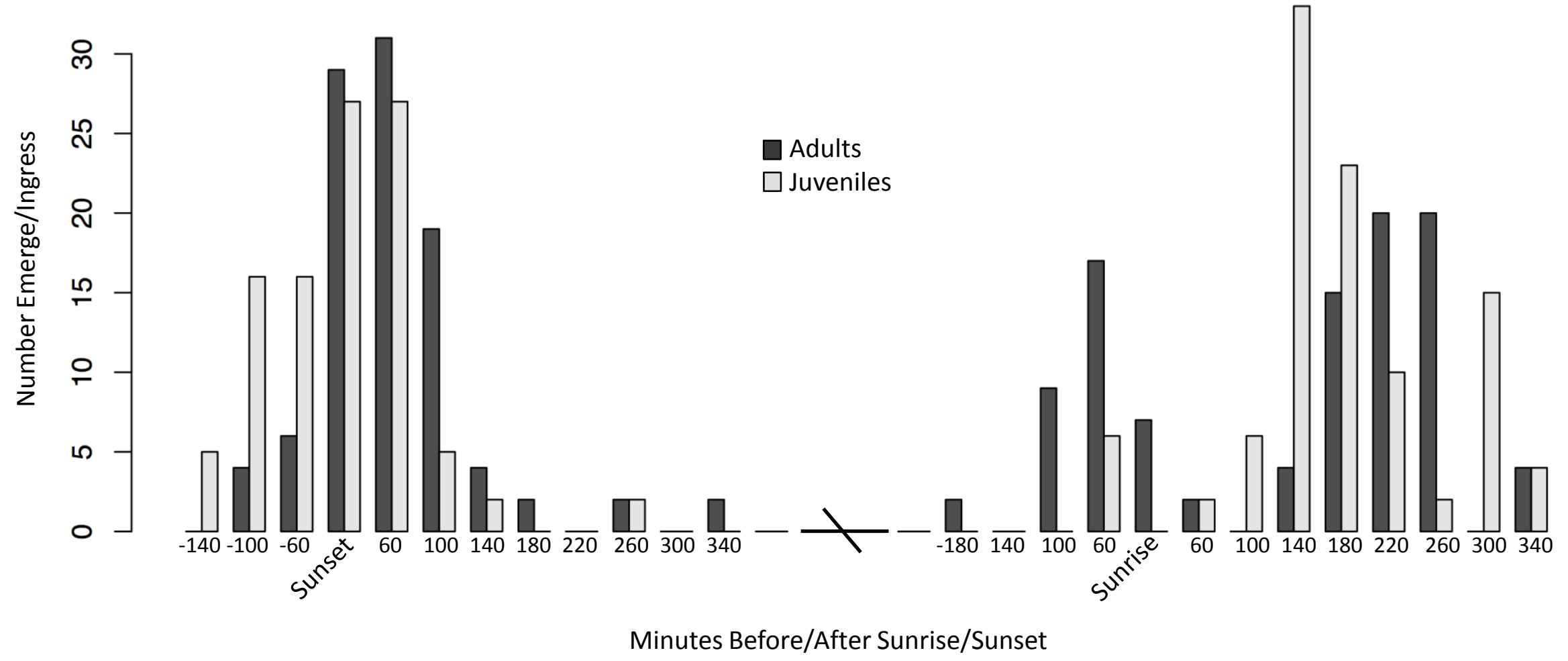




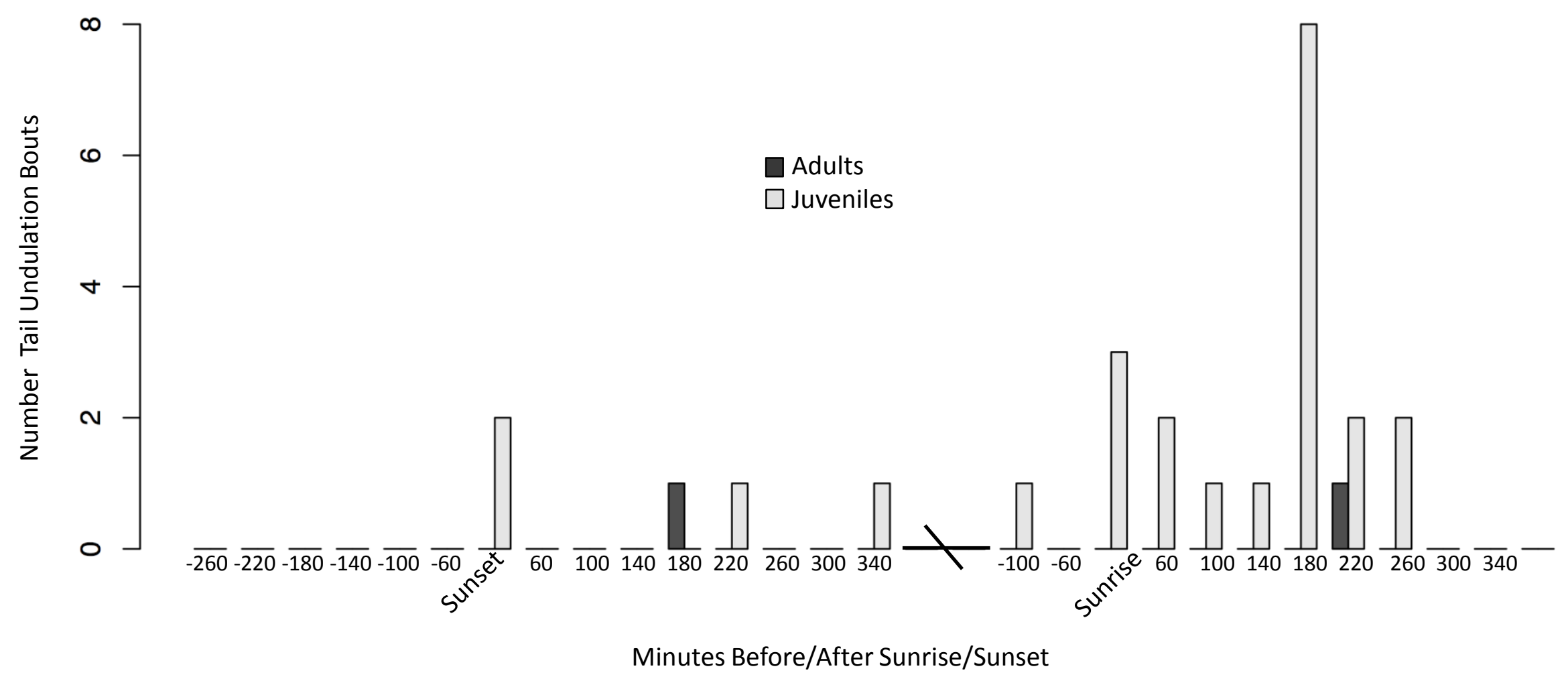




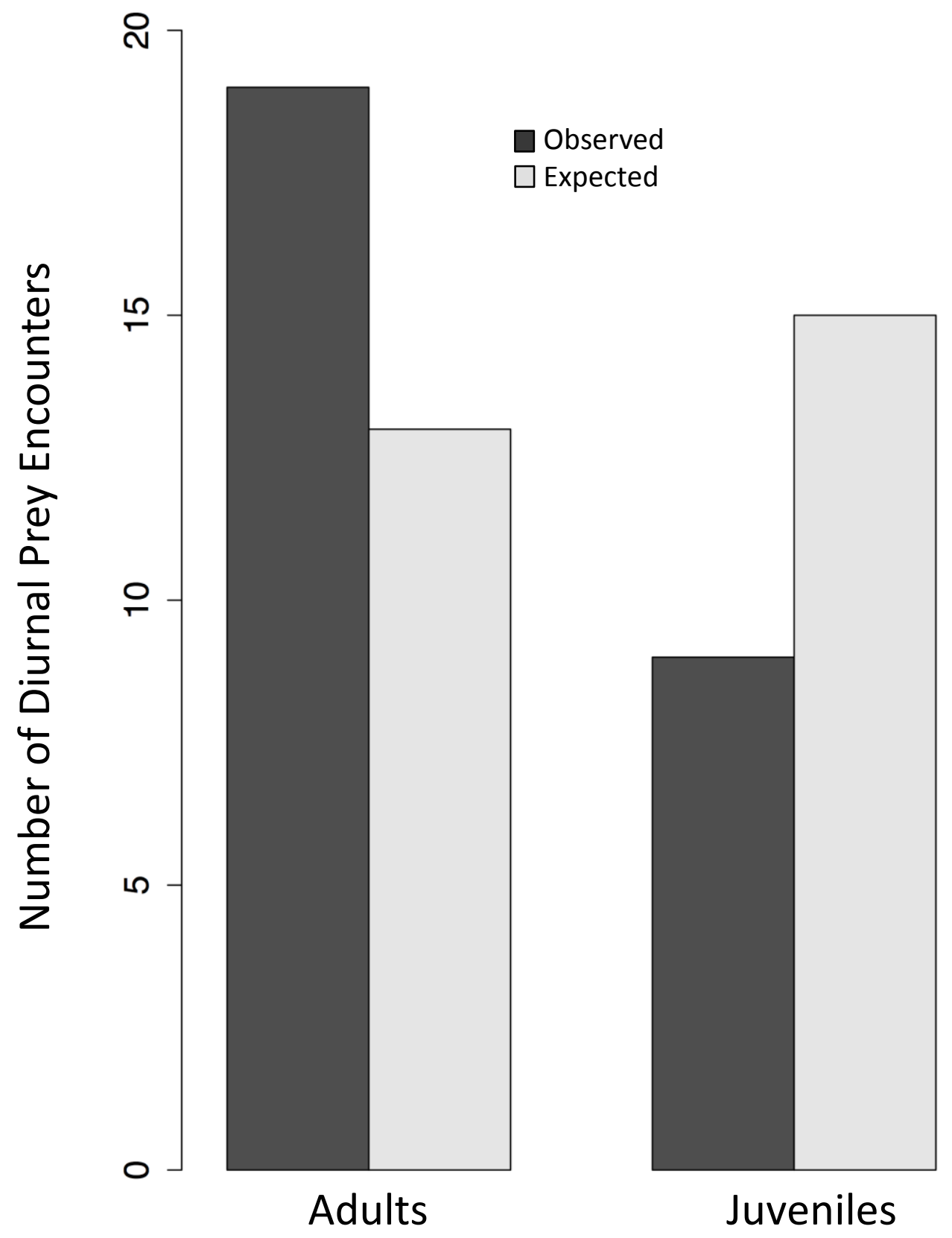

